\title{
Some Aspects of the Future Course of Polymer Research in Industry
}

\author{
H. RUDOLPH \\ Bayer AG, ZF-F, Central Chemical Research D-5090 \\ Leverkusen-Bayerwerk, West-Germany $(F R G)$
}

(Received August 20, 1984)

\begin{abstract}
In the light of the economic development of the main classes of polymers since the second oil crisis, people throughout the world are asking how much innovative potential there is in the polymer field and what the long-term prospects for these materials are. This report attempts to describe, with the aid of examples, the contribution made by industrial research to the qualitative and quantitative growth of polymers. Focus is set largely on research activities in polymer blends and composites, as well as on certain polymers with exceptional properties used in such highly specialized areas as electronics and medicine.
\end{abstract}

KEY WORDS Industrial Polymer Research / Economic Development of Plastic Production / Polymer Blends / Polymer Composites / Functional Polymers / Electroconductive Polymers / Polymers for Medical Application /

Polymers in industry-this term covers plastics, rubbers, and fibres as well as raw materials for coatings and adhesives, all materials of which many millions of tons are manufactured worldwide every year. The first figure gives a rough guess of the polymer consumption in 1984. Plastics are on top of the list dominating the polymer scenario. Consequently I think it is quite legitimate to take plastics as a basis for describing the current situation of the polymer industry and how it came about.

In the beginning of the seventies, following a period of sustained growth in plastics consumption, production in the Western world had reached 40 million tons and was expected to double within five years equivalent to an annual growth rate of $15 \%$. In view of the first energy crisis this forecast was revised, though not drastically enough, and a growth rate of $10 \%$ per year was predicted. At this rate, production would have doubled within 7 years. 5 years later, in the wake of the second energy crisis, the expected growth rate was reduced by about half, and since 1980 estimates have been even more conservative. We now expect growth of only $3.5 \%$ annually. If this figure proves to be accurate, the 100 million tons plastics consumption predicted 10 years ago for about 1980 will not be reached in fact until the year 2000. This would amount to a doubling of the current figure finally at the turn of the century (Figure 2).

We can only ever be sure about what has already happened. Forecasts are generally only extrapolations of the past and consequently they have to be revised so often. The effect of inaccurate forecasts, especially in the case of the commodity plastics, was that the creation of new capacity went racing ahead of actual sales.

In our economic region, Western Europe, which the next figures refer to, the existence of overcapacities became very clear as early as 1975 which was a bad year economically. The oil companies

$\begin{array}{lc} & \text { milliont } \\ \text { plastics } & 60 \\ \text { synthetic rubber } & 8 \\ \text { synthetic fibres } & 11 \\ \text { synthetic adhesives } & 3 \\ \text { binders for coating materials } & 4,5\end{array}$

Figure 1. Estimate of world consumption in 1984. 


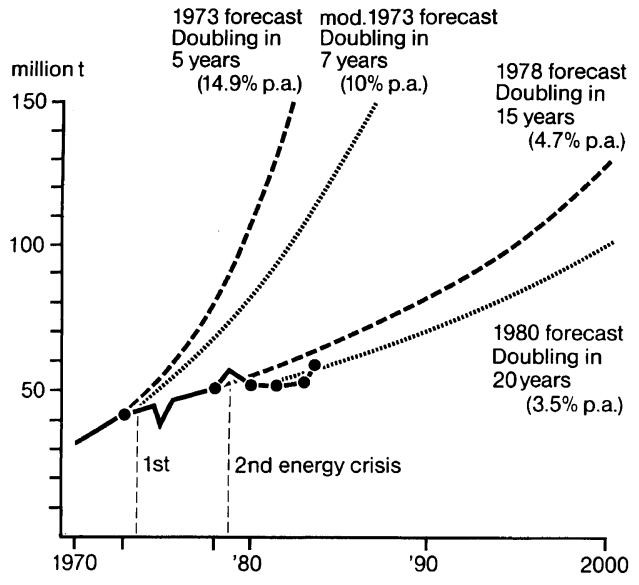

Figure 2. Forecasts of plastics consumption in the Western world and actual data.

and, in particular, the state-owned chemical companies, then increased their capacities still further, whereas the private-sector chemical companies carried out virtually no further expanison (Figure 3). The effect of this was to widen the gap between capacity and offtake (Figure 4). Pressure of competition prevented cost-related price increases. A real structural crisis occurred in commodity plastics, like in man-made fibres ten years earlier. From 1980 onwards the situation came to a head, with cumulative losses running into billions of dollars and plants having to be closed down to reduce excess capacity. The period of expansion in standard products came to an abrupt end.

How reacts industry when it gets into increasing difficulties with its standard products? Often the answer is to focus on products with a higher value added. And this automatically implicates research since research is normally expected to make substantial contributions to the development of higher value added products. A look at the history of polymer research indeed shows that the crucial impetus for the industry's development had its reason in research. Staudinger's brilliant elucidation of the principle of macromolecular structure, Carother's polycondensation theory and Ziegler's catalysis with organometallic compounds are examples of milestones in polymer research, each of which led to a boom in new useful polymers. Today we obviously look again to the innovative potential of reserach, from which we derive our hope and our confidence for the coming years.

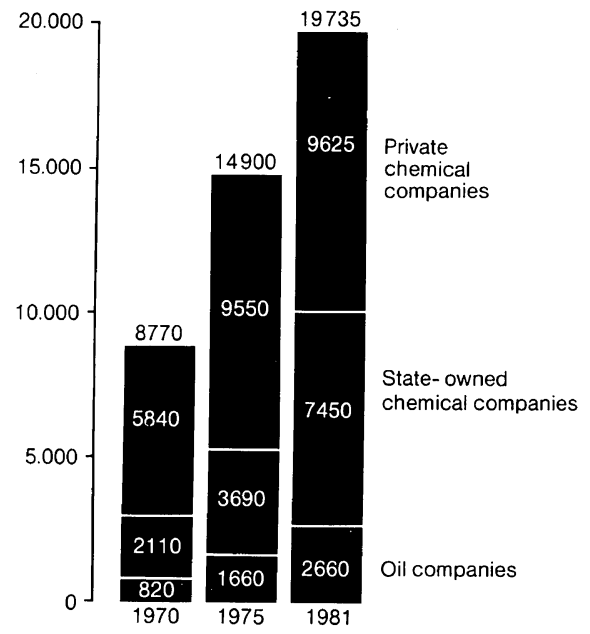

Figure 3. The "Big 5" thermoplastics in Western Europe. The development of capacities for the sum of LDPE, HDPE, PP, PVC, PS broken down to private chemical companies, state-owned companies and oil companies is shown for the period of 1970 to 1981 .

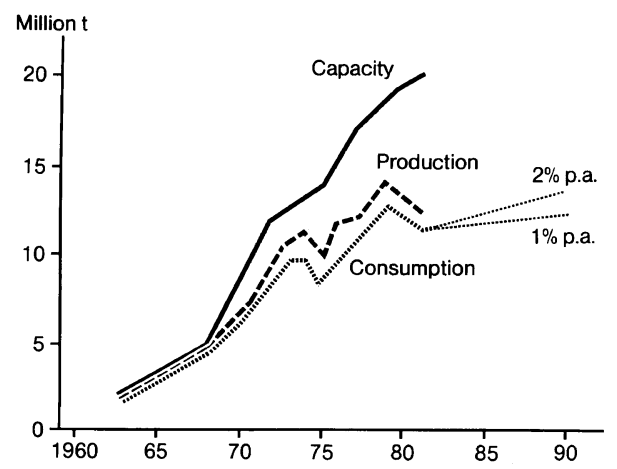

Figure 4. The development of capacity as compared to offtake is shown for the "Big 5" thermoplastics (LDPE, HDPE, PP, PVC, PS) in Western Europe for the period of 1970 to 1981 .

I would now like to outline certain areas where we believe the innovative power of polymer research is capable of yielding outstanding results which will be of significance to the continued development of the polymer industry.

\section{POLYMER BLENDS}

An increasingly important area of polymer research which we think will be of paramount importance tomorrow is the field of polymer blends. The 
idea of linking different monomeric compounds to random, block, or graft copolymers, is of long tradition in polymer science, and has already led to a wide variety of useful industrial products well established in the market place. The concept of polymer blends, however, is more comprehensive. It concerns physical mixtures in which the components of the mixture are, in most cases, themselves complex copolymers.

Research and development in the field of polymer mixtures has been initiated in industry in the 1940's. In 1948 Dow started the systematic development of improving brittle polystyrene by graft copolymerization on rubbers to result in commercial-scale production of HIPS in 1952. It took not too long until ABS was introduced to the market as an outstanding engineering material. In the 60 's the first single-phase polystyrene-containing blend-

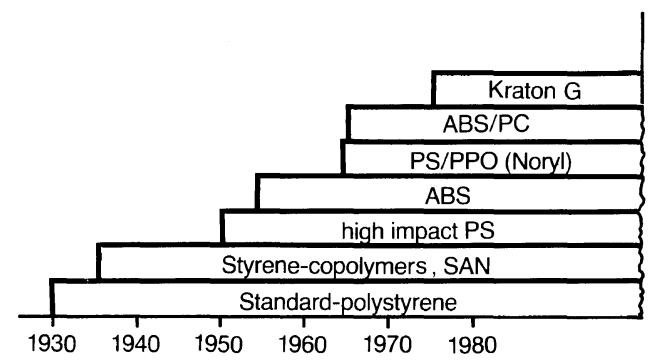

Figure 5. Brief survey of stages in the historical development of polystyrene.
PPO/PS, known as Noryl by General-Electricappeared. Figure 5 summarizes the stages in development of a polymeric material which started life more than 50 years ago as a brittle curiosity with a production of 60 tons/year, and which has now led to an appreciable range of high-quality plastics with production running to many millions of tons per year.

As a result of the success achieved in combining apparently uncombineable materials to produce useful blends, resarch efforts both in chemistry and physics of polymer blends led to an independent class of materials often exhibiting unexpected properties. Figure 6 shows a selection of current blends and in no way claims to present a complete picture.

Considering the accumulated wealth of knowledge already present today we have to ask ourselves what research in polymer blends might be aiming at in the upcoming years, and what products and methods can be employed? Demands to be satisfied or goals to be achieved may be set forth by future engineering technology as shown in Figure 7 featuring materials currently applied to manufacture bumpers or other automotive parts. All the materials mentioned here have been suggested to the automotive industry, some of them being already in use. The ideal, universal purpose product which combines the toughness of polycarbonate, the solvent resistance of polyamide, the flow properties of

\begin{tabular}{|c|c|c|c|}
\hline Composition & Typical Brands & (Manufacturer) & Outstanding Properties \\
\hline PVC/Acrylic & $\begin{array}{l}\text { Kydex } \\
\text { Acrylivin } \\
\text { DKE } 450\end{array}$ & $\begin{array}{l}\text { (Rohm and Haas) } \\
\text { (Gen. Tire \& Rub.) } \\
\text { (Sumitomo) }\end{array}$ & $\begin{array}{l}\text { Flame retardance, } \\
\text { Impact and chemical } \\
\text { resistance }\end{array}$ \\
\hline PC/ABS & $\begin{array}{l}\text { Bayblend } \\
\text { Cycoloy EHA }\end{array}$ & $\begin{array}{l}\text { (BAYER, Mobay) } \\
\text { (Borg-Warner) }\end{array}$ & $\begin{array}{l}\text { Lower cost, } \mathrm{HDT}=104^{\circ} \mathrm{C} \\
\text { Notched-impact resistance, } \\
\text { hardness, distortion temp. }\end{array}$ \\
\hline PP/EPDM & TPR & (Du Pont) & $\begin{array}{l}\text { Improved low-temperature } \\
\text { impact and flexibility }\end{array}$ \\
\hline SAN/Olefin & Polyman 552 & (Schulman) & Weather resistance \\
\hline PVC/ABS & Polyman & (Schulman) & $\begin{array}{l}\text { Flame resistance, self- } \\
\text { extinguishing }\end{array}$ \\
\hline & Cycovin KAF & (Borg-Warner) & Improved processability \\
\hline ABS/PSF & $\begin{array}{l}\text { Mindel A650 } \\
\text { Arylon }\end{array}$ & $\begin{array}{l}\text { (Union Carbide) } \\
\text { (U.S. Steel) }\end{array}$ & $\begin{array}{l}\text { Lower cost, more uniform } \\
\text { than former Arylon T }\end{array}$ \\
\hline Nylon/elastomer & $\begin{array}{l}\text { Zytel ST-801 } \\
\text { Durethan BC } 402\end{array}$ & $\begin{array}{l}\text { (Du Pont) } \\
\text { (BAYER) }\end{array}$ & Notched Izod impact \\
\hline PBT/PET & Valox 800 & (GE, GAF, Celanese) & Lower cost \\
\hline PPS/PTFE & BR 47,48 & (Phillips) & Lubricity \\
\hline PPO/PS & Noryl & (GE) & $\begin{array}{l}\text { Lower cost, } \\
\text { improved processability }\end{array}$ \\
\hline $\mathrm{PC} / \mathrm{PBT} /$ Elastomer & $\begin{array}{l}\text { Xenoy } \\
\text { Makroblend PR }\end{array}$ & $\begin{array}{l}\text { (GE) } \\
\text { (BAYER) }\end{array}$ & $\begin{array}{l}\text { Chemical resistance, } \\
\text { low temp.-impact }\end{array}$ \\
\hline
\end{tabular}

Figure 6. Selection of currently marketed polymer blends. 


\section{H. RUDOLPH}

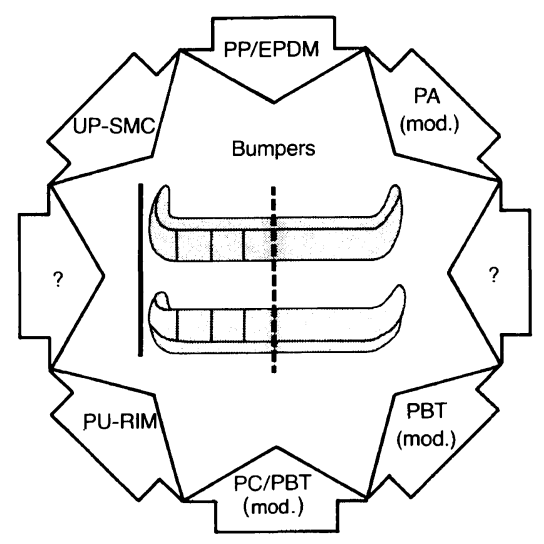

Figure 7. Engineering polymers as answers to an engineering problem like bumpers. An ideal material combining all desired properties is still a challenge to research.

PU-RIM, the heat resistance of polyimides, and last not least is as cheap as polyethylene has yet to be discovered. Materials asked for by today's users are of a more modest kind. But even limited requirements of the automotive industry present considerable practical difficulties to overcome.

The following two figures are presenting three examples of bumpers as parts of modern cars. First in Figure 8 the bumper parts of an Austin manufactured by British Leyland. The development of this product was based on PBT with its attractive properties like rigidity, hardness, abrasion resistance, good flow, high heat deflection temperature and easy mould release. Its toughness, however, is inadequate. Initial tests showed that SAN grafted polybutadiene can be a good modifier. Numerous experiments were necessary to determine how toughness was affected by a variety of parameters - e.g. degree of grafting, degree of crosslinking, particle size, degree of dispersion, molecular weight of the polyester before a material could finally be developed that meets the requirements of the automobile manufacturer.

Figure 9 shows two bumper sections. The top one, of Ford's Sierra, is made from a polymer blend of General Electric; the other - fitted as standard to the new Mercedes series - a Bayer material. Both these materials are three-component systems containing polycarbonate, polyester and an impact modifier.

Are we, the polymer producer, also satisfied? The

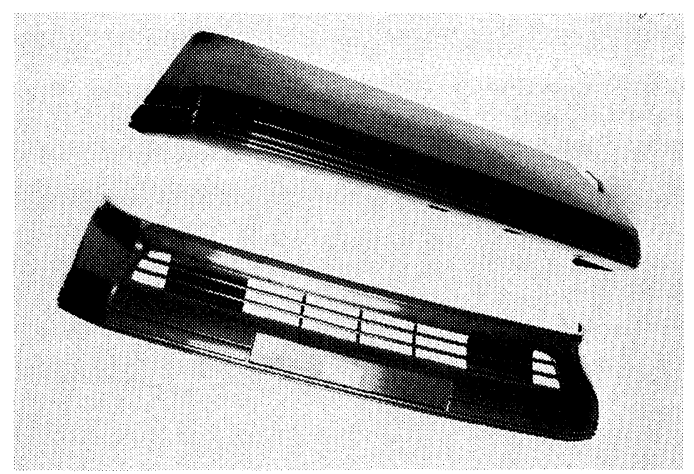

Figure 8. Bumper parts of British Leyland's Austin. Polymer used is Pocan, Bayer.

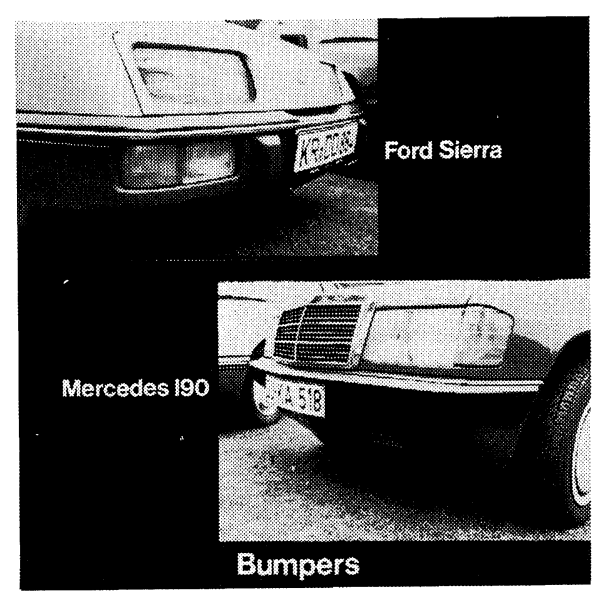

Figure 9. Top is a picture of the Ford Sierra bumper manufactured from Xenoy (General Electric), below is a picture of the Mercedes 190 bumper manufactured from Makroblend (Bayer).

answer must be no. The flow must still be improved, as well as the toughness at low temperatures. These demands define the direction in which future research will proceed in this particular case.

Leaving aside specific examples we have to ask more general questions like: What are the main requirements and what needs to be improved in the first place in polymer blends? Requirements may be envisaged as follows (Figure 10)

- Flow (processability)

- High-impact level at low temperatures like $-30^{\circ} \mathrm{C}$, in extreme cases down to $-50^{\circ} \mathrm{C}$

- Strength combined with toughness and dimensional stability

- Mechanical strength and chemical resistance up 


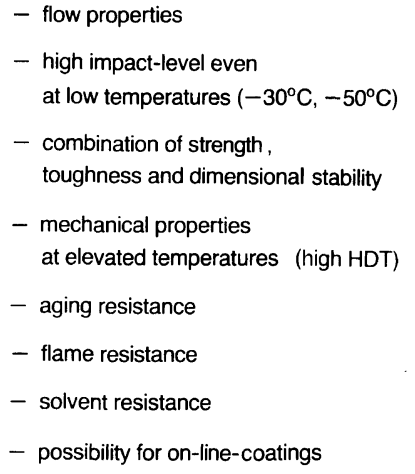

Figure 10. Polymer material properties are listed which require improvements.

to high temperatures

- Good ageing and long-term behavior

- Fire retardance

- Solvent resistance

- Good painting and electroplating properties.

Individual solutions are known to any one of these requirements. We are familiar with products which have excellent flow properties during processing and obtain their stiffness through crosslinking as is well known in the PU-RIM process. It is further well known that rubbers used as modifiers are able to make brittle materials tough. Stiffness may be obtained by crystalline morphology. Experience teaches that polyamides and polyesters are less susceptible to stress cracking and this list could be continued further.

Knowing well that individual polymers pose solutions to limited problems we may be led-or misled - to hope that there is a great opportunity in blending polymers to achieve the required combination of properties, combinations which are otherwise difficult if not impossible to obtain.

When blending polymers we are interested in the extent to which the properties can be changed as compared to the homopolymers. Three possible cases are demonstrated in Figure 11. "Additivity" may be observed, for example, in the modulus or in the heat resistance of single-phase compounds. Other material properties, such as stress or impact resistance at break are generally not obtained in a simple additive way. Often a minimum occurs as the composition is varied.

First let us have a look on single-phase systems. We know that specific interactions help to overcome the large entropic forces that oppose miscibility

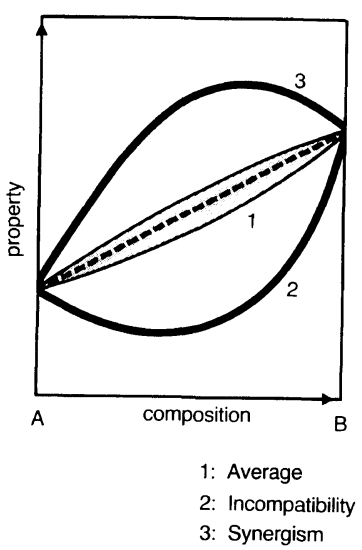

Figure 11. Three possible cases of the variation of properties is shown as composition of a binary blend is varied.

between different polymers. Such specific interactions may be proton bridging as in the case of poly(vinyl chloride)/polyester, aromatic coupling in the poly(phenylene oxide)/polystyrene systems, or dipolar interactions as in the poly(vinylidene fluoride)/poly(methylmethacrylate) system. Rewards offered by single phase systems of this kind are continuously adjustable properties as mixing ratio is changed and occasionally synergistic effects in strength values.

Figure 12 shows the heat distortion temperature of a poly(vinyl chloride)/polycarbonate system. The advantages of the "polymer plasticiser" can be recognized easily and in our opinion this compound deservers more interest than it received up to now.

Of larger importance, however, are multiphase systems. They constitute the majority of blends because the entropic forces in most cases dominate and consequently phase separation is observed. The key to the success of such blends is the interfacial adhesion. We have to learn how to control and exploit this phenomenon in order to improve properties.

Traditional and less traditional approaches may be chosen. The oldest approach is to combine the thermoplastic component $\mathrm{A}$ with a modifier B which for instance can be A altered by copolymerization or graft copolymerization. A more attractive method is to attain interfacial adhesion by the aid of compatibilizers which settle at the interface where they bring about the required effect between the compounds A and B usually by selective miscibility 


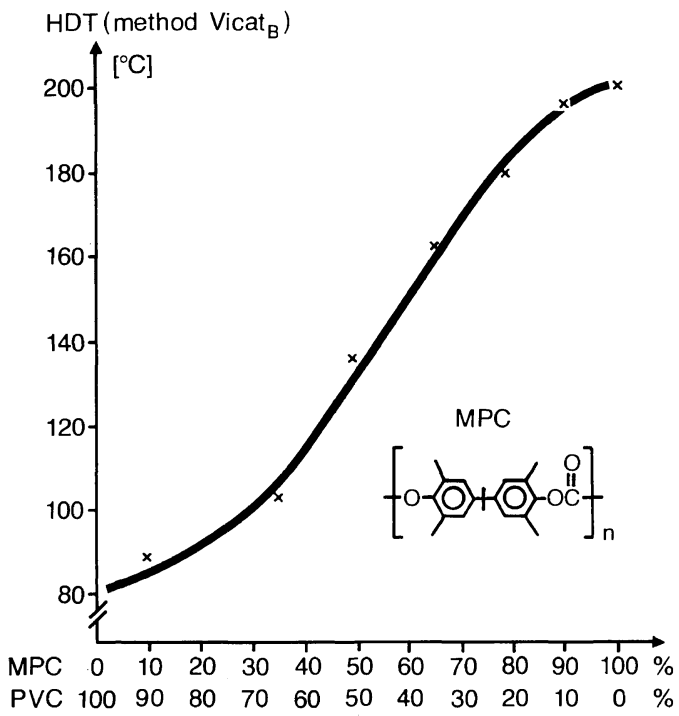

Figure 12. The heat distortion temperature of a blend of a poly(tetramethylbisphenol A) carbonate and poly(vinyl chloride) is shown as composition is varied.

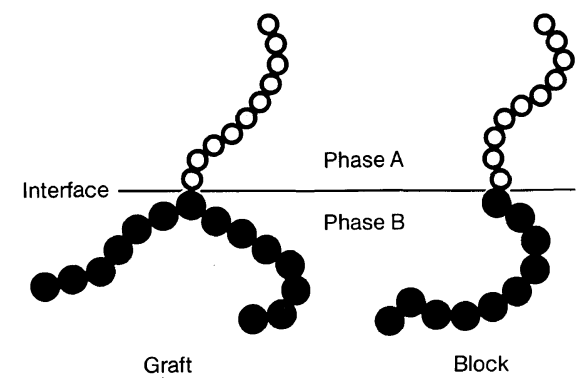

Figure 13. Schematic model of polymeric compatibilizers at a blend interface.

(Figure 13). The development of compatibilizers presents a challenge to chemical synthesis particularly if new block and graft copolymers are required. New monomers might take part in the game. Recently we have gained useful experience in the modification of polyamides by using copolymers of $N$-vinyl- $N$-acyl-monomers.

The molecular architecture-random, block, or graft-is, however, undoubtedly more important. Great attention must be paid to synthetic techniques like anionic polymerization in order to "tailor-make" polymers. A challenge to polymer synthesis is to harness Ziegler-Natta type and cationic polymerizations in a similar manner like

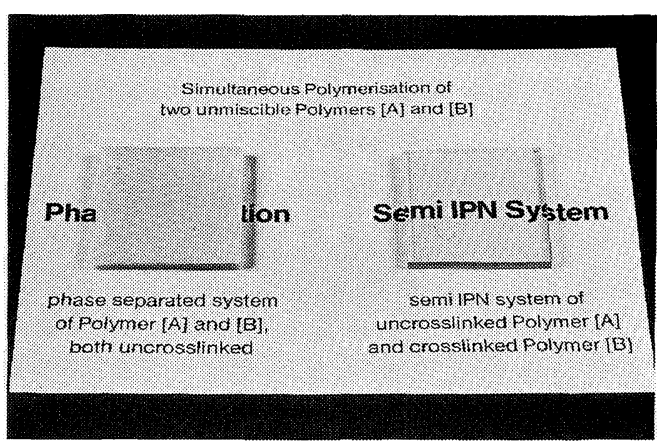

Figure 14. A phase-separated, turbid material is obtained when polymer $\mathrm{A}$ and $\mathrm{B}$ are simultaneously prepared. A transparent material is obtained when B is simultaneously crosslinked.

it is known for anionic polymerization.

Another method to prevent phase segregation is the formation of interpenetrating networks (IPN). What, however, really is the state of our knowledge on IPN's? The formation of a polymer, e.g. of a polyurethane network, in presence of another polymer, e.g. of a polyacrylate, cannot be regarded as the formation of a truly interpenetrating network even though the product may exhibit a single broad glass transition or transparency. Systems of this structure have been called "semi-IPN" in contrast to an ideal IPN consisting of two molecular networks, forming a fabric on a molecular scale (Figure 14). It remains a challenge to polymer science to prove the existence of a truly IPN.

Frankly speaking the development of new blends today is still very much a matter of trial and error. To illustrate this we may take a look at the history of developments in polymer blends. Initially there was compounding_-a practical method with no theoretical ramifications. The first important theoretical work dealing with the thermodynamics of mixing in polymer science was taught to us by Huggins and Flory. Today we still have a long way to go as far as the understanding and prediction of polymer blends is concerned. In order to make progress in this area, we need to develop

- methods of characterizing interfacial phenomena in the molten and solid states, including the characterization of the interfacial forces

- a method to control the kinetics of phase separation

- and methods of characterizing the morphology of 
polymer blends and their deformation mechanisms.

If we succeed to translate the theories and results of polymer physics into the preparative polymer chemist's language-for example in projects tackled jointly by universities and industrial laboratoriesthe essential requirement for progress in the highly interesting field of polymer blends can be met.

\section{FIBRE-REINFORCED COMPOSITES}

Another area of increasing interest to the polymer industry is that of fibre-reinforced composites, in particular the use of continuous fibres. Figure 15 presents a compilation of polymer matrices used in composite materials. Figure 16 gives a compilation of the reinforcing fibres now in common use. By combining the plastic material with continuous reinforcing fibres the tensile modulus can be increased up to 50 fold. An impressive picture is given by the comparison of the tenacity of various materials (Figure 17). The combination of excellent mechanical properties and of low weight renders interesting potentials to fibre-reinforced materials in engineering applications.

As an illustrative example of the current state of technology may serve the Polystal system, a Bayer development. Polystal consists of a UP resin matrix and large numbers of continuous glass fibres with a defined prestress combined with synthetic fibres. A remarkable combination of properties as compared to steel is shown by Figure 18. A truck can be carried by a Polystal wire as is seen in Figure 19.

The application of carbon fibres in composite materials is shown in Figure 20. By comparing the figures of 1980 with those of 1982 one can see clearly how the consumption of reinforcing fibres has increased and how certain applications have advanced relative to others. Composite materials have been welcomed particularly in the aerospace industry. In Figure 21 high-performance composite materials are listed which are used in a modern aircraft, materials in which the reinforcement is provided by carbon or aramide fibres.

Weight savings, reductions in maintenance and manufacturing costs are the factors why producers of composite materials look for opportunities in other attractive markets like automobile production. The aerospace applications can be regarded as an attractive inroad to a wider market. In May 1984

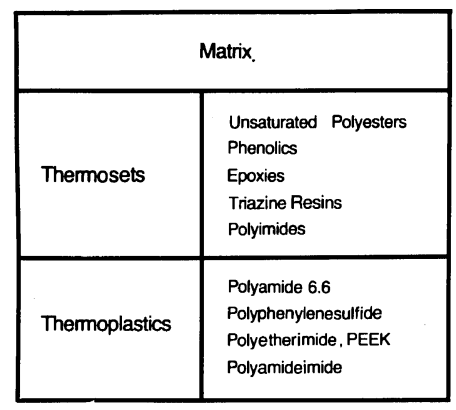

Figure 15. Thermosets and thermoplastics used as matrix resins in composites.

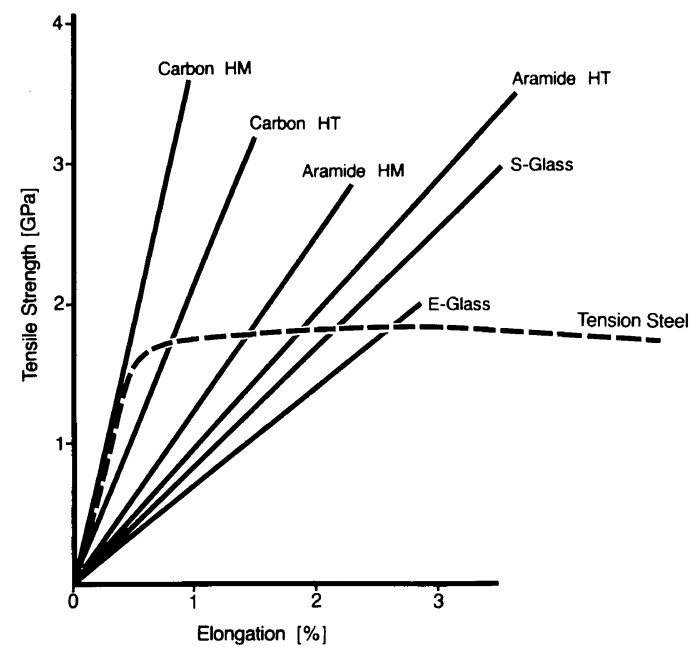

Figure 16. Tensile strength of various rein-forcing fibres used in composites.

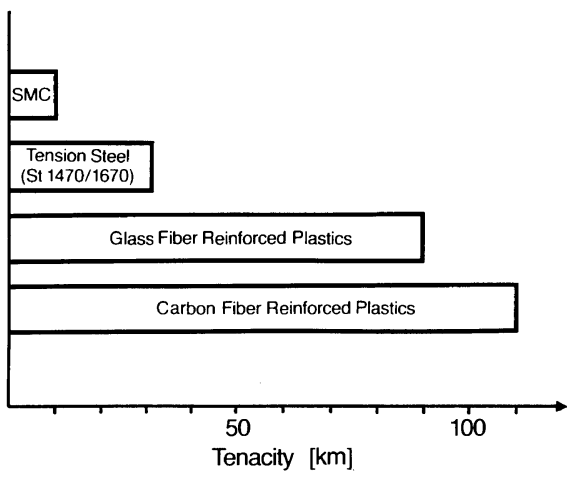

Figure 17. Comparison of tenacity of various composite materials. 


\begin{tabular}{|c|c|c|}
\hline & Polystal & $\begin{array}{c}\text { Tension Steel } \\
\text { St } 1470 / 1670\end{array}$ \\
\hline $\begin{array}{c}\text { Tensile Strength } \\
{[\mathrm{GPa}]}\end{array}$ & 1,60 & 1,67 \\
\hline $\begin{array}{c}\text { Elongation at Break } \\
{[\%]}\end{array}$ & 3.2 & 6.3 \\
\hline $\begin{array}{c}\text { E-Modulus } \\
{[\mathrm{GPa}]}\end{array}$ & 50 & 210 \\
\hline $\begin{array}{c}\text { Tenacity } \\
{[\mathrm{km}]}\end{array}$ & 76 & 21.5 \\
\hline $\begin{array}{c}\text { Density } \\
{\left[\mathrm{g} / \mathrm{cm}^{3}\right]}\end{array}$ & 2.1 & 7.85 \\
\hline
\end{tabular}

Figure 18. Mechanical properties of Polystal (Bayer) as compared to tension steel.

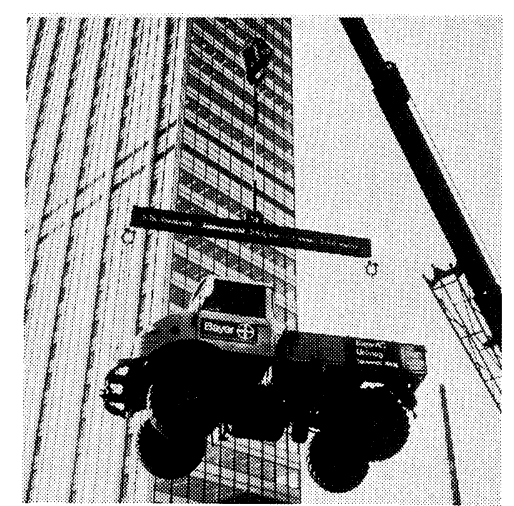

Figure 19. Strength of Polystal is demonstrated by its ability to carry heavy loads like a truck.

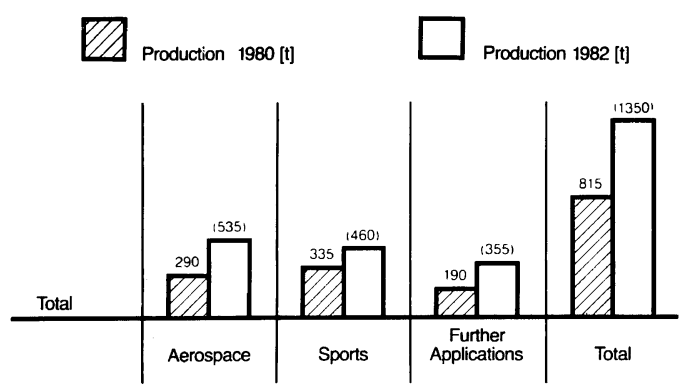

Figure 20. World production of carbon fibres and their use in aerospace, sports and other applications.

the first public test of a racing car engine containing many fibre refinforced plastic components took place. Connecting rods, tappets, valve spring retainers, timing gears, piston skirts and piston pins are made of a carbon reinforced thermoplastic polyamide-imide resin which can maintain struc-

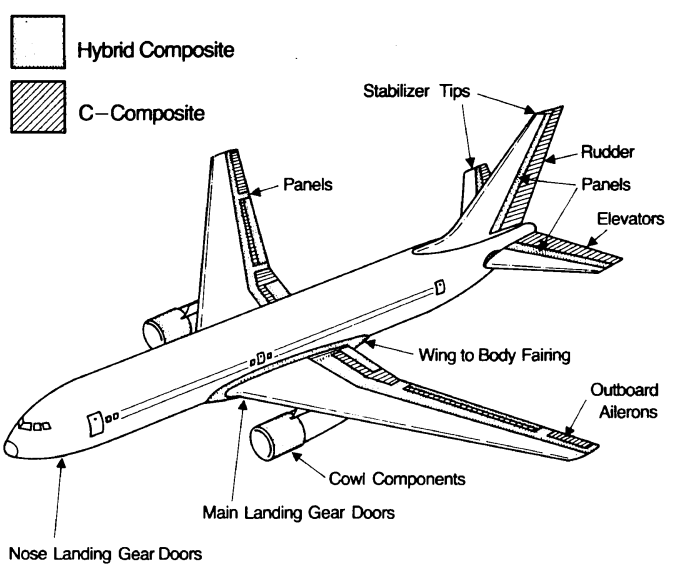

Figure 21. Composite materials used on a modern aircraft (Boeing 767).

tural integrity up to temperatures of $260^{\circ} \mathrm{C}$. The block, cylinder head, cam cover, and oil pan are made of a thermosetting epoxy resin, reinforced by woven carbon fibres. The engine, constructed by Polymotors Inc., contains about $27 \mathrm{~kg}$ of metal, $25 \mathrm{~kg}$ of plastic and $18 \mathrm{~kg}$ of fibres. It is about $80 \mathrm{~kg}$ lighter than conventional engines of comparable size. Since 1981 General Motor's "Corvette" is equipped with a $3,6 \mathrm{~kg}$ plastic leaf spring. It consists of glass, Aramide and Boron fibres embedded in an epoxy-matrix. General Motors intends to produce 5 millions of these springs until 1988.

The aerospace industry with its highly exacting demands and the motor vehicle industry with its undeniably more attractive market are orientation marks according to which the emphasis will be placed in future research work. Figure 22 lists the demands that will have to be met in the foreseeable future. The demands apply to the matrix resins, to the fibres, to the combination of both, and to processing techniques. Figure 22 sums up what has to be expected of matrix resins in the future.

- The total elongation at break will have to be increased to at least 6 per cent without loss of strength. If we do not succeed in this respect, further developments in the strength of fibres will be of no value as interfibre failure would render the parts useless.

- Next creep behavior has to be improved. Fibrereinforced plastics to be used as engine components must exhibit a creep behavior roughly the same as that of metals to allow the use of 
1.) Increase of Elongation at Break to $\geq 6 \%$

2.) Improved Creep Behavior

3.) Improved Heat Resistance

4.) Lower Moisture Pick-Up

Figure 22. Requirements for the development of matrix resins to be used in composites.

prestressed parts.

-In certain applications-propulsion units, for example - matrix systems must possess excellent heat stability. The availability of matrix systems allowing use temperatures up to $250^{\circ} \mathrm{C}$ would open a wide range of applications.

- Both high temperatures and high moisture absorptions decrease the strength of carbon fibre/ plastic laminates. Moisture absorption has to be reduced.

An example of the problems to be dealt with are the temperatures and temperature differences measured on the supersonic Concord plane during various stages of a flight as can be seen in Figure 23.

Additional requirements which must be met by the matrix resins are improved processing, mainly reduction in setting times and setting temperatures, improved flame-retardance and minimization of smoke gas formation, in particular toxic smoke gas constituents. Finally resistance to organic media like hydraulic fluids, liquid fuels, and lubricants has to be improved. There is no doubt that solutions to the various problems are beginning to appear.

Thermoplastics used as matrix resins exhibit high elongation at break, high tensile strength and are often less adversely affected by air humidity as compared to thermosets. Their main drawback is poor processability because of their high viscosities in the molten state. Thermally stable resins of several types with large numbers of possible modifications have been described in the patent literature. They are based on imide groups and are variously packaged as polyimides, polybenzimidazoles, polyquinoxalines, and derivatives of maleic imide. Polyimides in general combine high continuous service temperature, favourable flame retardance, and resistance to solvents. Their drawbacks are mainly in the area of mechanical properties. Here,

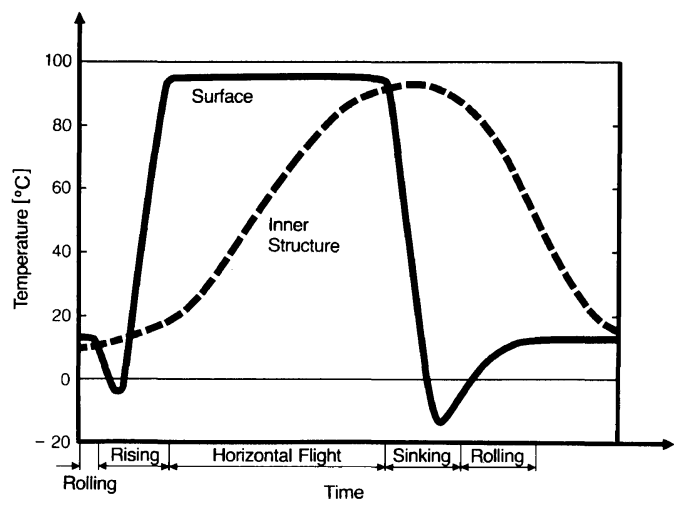

Figure 23. Temperature of surface and structure of a supersonic civil aircraft (Concord) during a transatlantic flight.

again, there is no ideal solution.

A brief comment, now, on the fibres. If the theoretically possible mechanical property data of materials are compared to those actually measured in compact and fibrous materials, the situation is as shown in Figure 24. Thus, whatever material is concerned, it is clear that we have by no means exhausted the theoretical potentials. This fact necessarily opens up a wide field of research. We have to learn how to develop a reinforcing fibre which permits closest possible approximation of the theoretically attainable values.

How the strength of polymeric composite materials can be increased by molecular orientation is demonstrated in the example of ultra high modulus fibres. In Figure 25 is shown how the stiffness values of polyethylene depend on the spatial orientation of the molecular chains. From Tadokoro's stiffness matrix of polyethylene it is evident that the strength in the direction of the main molecular chain is more than thirty times greater than the strength values perpendicular to it. Ward has demonstrated how special extrusion techniques enable the theoretically possible strength values to be approached.

Contemplating the crystalline and amorphous domains of an ultra high modulus polyethylene, as represented schematically in the right part of Figure 25 , we realize that this material is on a molecular scale analogous to fibre reinforced composite materials. Polyethylene might be regarded as a composite material consisting of oriented domains in a non-oriented matrix. In this case the fibre equivalent domains are particularly well connected with 


\begin{tabular}{|l|l|c|c|}
\hline \multirow{2}{*}{} & \multicolumn{3}{|c|}{ Tensile Strength [GPa] } \\
\cline { 2 - 4 } & Fiber & $\begin{array}{c}\text { Non-Oriented } \\
\text { Material }\end{array}$ & $\begin{array}{c}\text { Possible } \\
\text { (Theory) }\end{array}$ \\
\hline $\mathrm{Al}$ & 0.8 & 0.6 & 3.8 \\
$\mathrm{Fe}$ & 4.1 & 1.4 & 11.2 \\
\hline $\mathrm{HDPE}$ & 1.0 & 0.03 & 25 \\
Polyamide 6.6 & 0.85 & 0.08 & 25 \\
Aramide & 3.0 & - & 25 \\
\hline Carbon & 3.0 & $(0.1)$ & 35 \\
\hline $\mathrm{Glass}$ & 4.0 & $(0.1)$ & 11 \\
$\mathrm{Al}_{2} \mathrm{O}_{3}$ & 1.6 & 0.2 & 26 \\
\hline
\end{tabular}

Figure 24. Comparison of practical obtainable and theoretical tensile strength values of various materials.

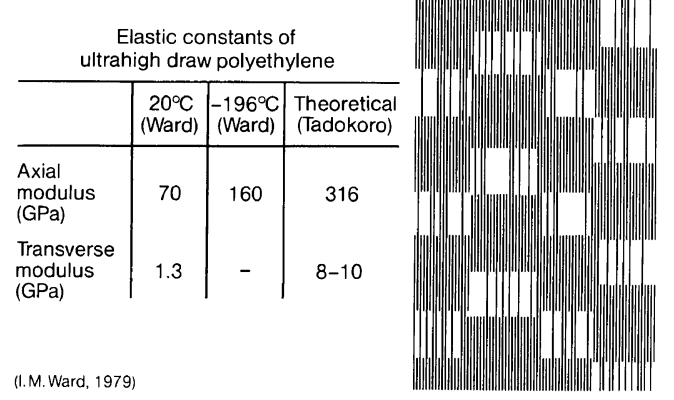

Figure 25. Elastic constants of ultrahigh modulus polyethylene (left) and an idealized representation of the crystalline phase in ultrahigh modulus polyethylene (right).

the amorphous matrix. It may be worthwhile to exploit the potentials of composite materials already at the molecular level. Self-reinforcing materials may be the reward of this research. In the well known and widely debated case of liquid crystal polymers the combination of rod or worm like polymeric chains and amorphous chains with a relatively shorter persistence length preferably on a molecular level may eventually result in a composite material of the future.

Our knowledge on how the fibre matrix interface affects the load-bearing behaviour, long-term stability, and mechanical characteristics of composite materials is still inadequate. It is known at present that the fibre production process, fibre service treatment, and fibre coating have a decisive influence on the interface behaviour. The efforts of improving the adhesion of rubber to various fibres in modern radial tires can be considered as a typical example. Examination of the correlations between descriptions of surfaces and the properties of corresponding composites will permit conclusions that could be useful in further development work.

A word, finally, on the processing which needs to be improved too. The aircraft industry can still afford the complex curing operations that are quite usual in the case of fibre composites but this is definitely not true of the motor vehicle industry. Suppliers of fibre composites who wish to gain a foothold in the motor vehicle industry must appeal not only to the chemist to provide them with products having shorter curing times and lower curing temperatures but in particular to the engineer whose responsibility is to produce the parts in question in the best possible way.

The winding technique has been known for a long time but is now just beginning to gain the breakthrough which could eventually result in large-scale production. No method analogous to the winding technique is known so far which could enable the production of fibre reinforced components with surfaces large in relation to their volume to compete with parts produced by deep-drawing of metal sheet. It is a challenge to the engineer to find a solution to this problem. An enormous market for fibre reinforced composites could be opened up by new material adapted engineering techniques.

Conclusions in the field of composite materials can be drawn in the following manner. Future research will have to deal mainly with the development of better matrix resins. Further improvements in the properties of fibres will be of little value if the elongation at break of the matrix is not decisevely increased. Fibres will have to be produced less expensively. Equal in importance to new matrix resins are both the further development of knowledge relating to fibre matrix bonding and the development of engineering processes suitable for the streamlined mass production of reinforced plastic components.

\section{SPECIAL POLYMERS AND CONCLUDING REMARKS}

Besides plastics the other major types of polymeric materials, fibres, rubbers, coatings and adhesives, of course, present their own challenges. In the fibres field there is the desire to produce up 
graded products for industrial purposes more cheaply. In rubber further research is being carried out on networks to obtain a better understanding of the structure of rubber so that its properties can be more easily manipulated. An exciting goal for research in coating is a solventfree coating system, absolutely unobjectionable from the environmental point of view and equally suitable for metal and plastics substrates. In the adhesives field researchers hope to come up with a high-performance adhesive capable of replacing screw joints.

The researcher's imagination is excited even more by the ability of certain polymers to gain a foothold - sometimes quite unexpectedly - in specialized applications outside the main areas mentioned. Figure 26 shows some of these functional applications of polymers. In information technology electro- and photoconductive polymers may serve as memory and recording materials, display or conversion devices, optoelectronic sensors. In separation technology for instance water treatment needs to be improved by approaching reverse osmosis theory. Ion-exchange membranes, ore enrichment, enhanced oil recovery and biomass separation are areas of considerable interest to polymer developments. Biofunctional materials stimulate research in particular. Of interest are not only materials for medical engineering like artificial organs or slow-release drugs but also biomimetic materials like biomembranes, polymeric drugs, and the specific targeting of drugs. This list indicates what certain polymers can achieve in specific areas without claiming to give a complete picture, however, the versatility of polymers is illustrated. I confine myself to two aspects of research on these special polymers. First, a comment on electro-conductive polymers is made.

Usually insulators, certain polymers can be made to conduct electricity by doping, i.e., by oxidation or reduction. Figure 27 shows some examples. Polyacetylene, polypyrrole and polyphenylene after the addition of a doping agent exhibit electrical conductivities of $10^{3}$ up to $10^{4} \mathrm{~S} \mathrm{~cm}^{-1}$, about the same as that of metals. There have been many attempts made until recently to turn polyacetylene, in particular, into more than just a curiosity prepared in the laboratory. There are, however, major drawbacks.

- The polymer is insoluble and will not melt, and

\begin{tabular}{|c|c|c|}
\hline $\begin{array}{l}\text { Information } \\
\text { Technology }\end{array}$ & $\begin{array}{l}\text { Separation } \\
\text { Technology }\end{array}$ & $\begin{array}{l}\text { Biofunctional } \\
\text { Materials }\end{array}$ \\
\hline $\begin{array}{l}\text { Electro- } 7 \text { conductive } \\
\text { Photo- } \text { Polymers } \\
\text { - memory and } \\
\text { recording } \\
\text { - dispiay devices } \\
\text { - conversion devices } \\
\text { - sensors }\end{array}$ & $\begin{array}{l}\text { Membranes } \\
\text { - water treatment } \\
\text { - ion exchange } \\
\text { - gas separation } \\
\text { Biomass separation } \\
\text { Ore enrichment }\end{array}$ & $\begin{array}{l}\text { Medical Engineering } \\
\text { - slow-release drugs } \\
\text { - artificial organs } \\
\text { Biomimetic Materials } \\
\text { - biomembranes } \\
\text { - polymeric drugs } \\
\text { - targeting of drugs }\end{array}$ \\
\hline
\end{tabular}

Figure 26. Functional applications of polymeric materials in advanced or future technologies.

a) $+\mathrm{CH}=\mathrm{CH}+\mathrm{CH}=\mathrm{CH}-\cdots \cdots \cdots \cdot$

Polyacetylen $\quad \delta_{\mathrm{AsF}_{5}-\text { doped }} \sim 10^{+3} \mathrm{~S} / \mathrm{cm}$

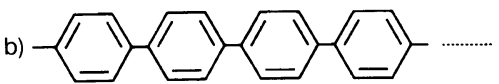

Polyparaphenylen $\quad \delta \mathrm{AsF}_{5}$-doped $\sim 10^{+2} \mathrm{~S} / \mathrm{cm}$

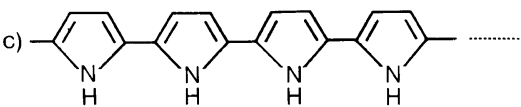

Polypyrrol $\quad \delta_{\mathrm{BF}_{4}^{-}-\text {doped }} \sim 10^{+2} \mathrm{~S} / \mathrm{cm}$

Figure 27. Some examples of conductive polymers.

therefore cannot be processed easily.

- It exhibits satisfactory conductivity only after doping with highly toxic and volatile agents such as arsenic pentafluoride or iodine.

- The electrical conductivity can only be maintained for a limited period of time and cannot be permanently stabilized.

The elimination of these disadvantages is still one of the principal aims of research.

For example, a polyacetylene which is processable by methods normally used for nonwovens, has been realized by developing a crab-shaped polyacetylene modification (Figure 28). This polyacetylene allows the production of films or coatings of any desired geometry and thickness. The doping agent used is ferric chloride which is neither toxic nor volatile. Insufficient stability, however, has not been solved satisfactorily despite many patent applications in this field and continues to present the most difficult problem to the use of polyacetylene. The challenge of the future is either to achieve a breakthrough in this question or to find new poly- 


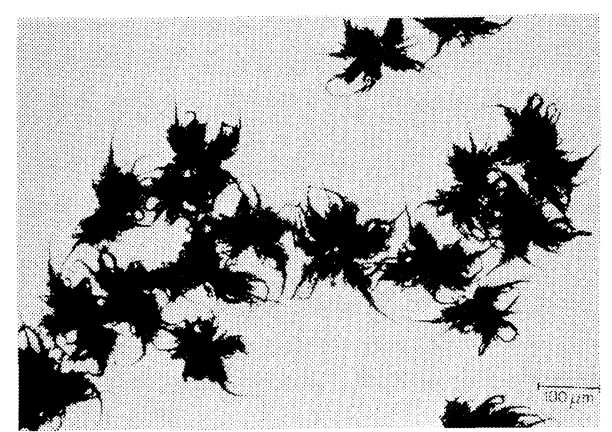

Figure 28. Crab-shaped polyacetylene (Bayer).

mers exhibiting permanent electroconductivity.

The industrially oriented chemist, however, has to ask what purpose we need polymers with metallike conductivity for. A special case may be the activities to produce a useful polyacetylene battery. The first paper on this subject was published by MacDiarmid and Heeger. A number of companies have been carrying out developments in this application. Nothing is known at present of the progress made in developing a lighweight battery from polyacetylene.

It is much easier to answer what electroconductive polymers can be used for if we do not insist that the materials exhibit a metal-like electroconductivity. Polymers with electric conductivities of the order of $10^{-10} \mathrm{~S} \mathrm{~cm}^{-1}$ to $10^{-9} \mathrm{~S} \mathrm{~cm}^{-1}$ are required for antistatic moulded parts, films and fabrics. A level of conductivity of $10^{-1} \mathrm{~S} \mathrm{~cm}^{-1}$ to $10^{-2} \mathrm{~S} \mathrm{~cm}^{-1}$ is needed for the electromagnetic shielding of electronic equipment like data processing equipment, television receivers, electronic typewriters and electronic automotive components.

Conventional methods of increasing electric conductivity of polymers are to add conductive fillers, such as metals or carbon black, or to coat the surface with metals by vacuum metallization, flame spraying or chemical plating. These methods are unsatisfactory, partly because they are highly elaborate and therefore expensive, and partly because a high filler content may result in plastics with poor mechanical properties. One way in which progress has been made is the development of suitable charge transfer complexes for use as fillers to increase conductivity. By virtue of the filamentary structure of certain CT complexes based on TCNQ a network of conductive paths can be obtained with a filler content of as little as $0.5 \%$ by weight resulting, for

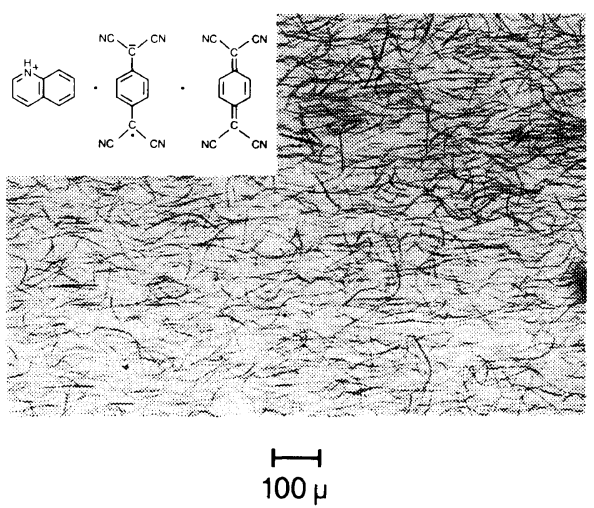

Figure 29. Antistatic polycarbonate film by admixing $0.5 \%$ TCNQ-complex salt (Bayer).

example, in permanent antistatic films (Figure 29). Due to the negligible filler content the plastic properties are virtually unaffected. Additionally these films have a degree of transparency required in many applications.

Research in this field is focused on replacing the expensive TCNQ by cheaper and more stable acceptors which impart the same degree of conductivity at significantly lower concentrations. Once again we try to answer the question whether to look for new polymers as conductive as metals or to focus our efforts on additives, small amounts of which are capable of imparting to plastics the fairly low level of electric conductivity essential to many applications without affecting the mechanical properties. We prefer this second course of research since it involves objectives which we believe are quite possible to attain.

Finally a few comments on medical applications of polymers. Figure 30 gives an outline of what polymers can achieve in medicine. The main applications of polymers are as components for artificial limbs and organs, polymeric membranes for blood dialysis, polymeric plasters for transdermal application and polymers as pharmacologically active substances. The field that stimulates the imagination most of all is surely that of pharmacological active substances. We have to distinguish, however, slow-release pharmaceuticals, i.e., compounds having a polymeric component whose function is to release an active ingredient slowly, from materials which are pharmacological active themselves.

The most thoroughly investigated anionic polymer from the medical point of view is Divema or 
1. Polymeric materials for artificial bones, joints, blood-vessels and organs

2. Polymer membranes for the artificial kidney

3. Polymeric devices for the administration of drugs

4. Polymeric drugs

Figure 30. Biomedical applications of polymers.

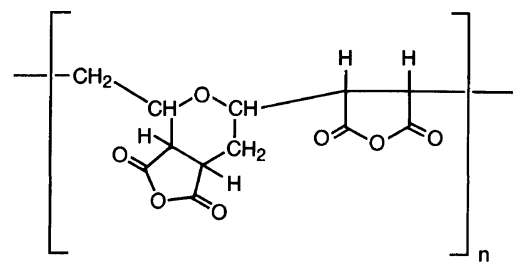

Figure 31. Structural formula of Divema (Hercules Inc.).

pyran copolymer synthesized by Hercules in 1964 (Figure 31). This is a cyclocopolymer of one mol divinyl ether and 2 mol maleic anhydride. This polymer is biologically active in a number of ways, it is effective as an anti-tumor agent, induces Interferon and has antiviral, antibacterial and fungicidal action. Eventually was discovered that Divema inhibits blood clotting and inflammation. Unfortunately, the acute toxicity of this product is very high. An investigation of its properties as a function of molecular weight showed that its toxicity and antiviral effectiveness are significantly reduced with decreasing molecular weight, whereas its effectiveness as an anti-tumor agent is little affected. Nothing is yet known how effective Divema is as an anti-tumor agent in man.

Chemical experiments with another anionic copolymer of Monsanto were reported in 1980 (Figure 32). This product is prepared from ethylene/ maleic anhydride copolymers of very low molecular weight by reaction with ammonia and subsequent imidization. Since in several tumor models the product displayed a significant tumor-inhibiting effect it is now undergoing further clinical tests.

At Bayer we have discovered in recent years that non-ionic, water-soluble copolymers also significantly inhibit tumors in various tumor models and are of very low toxicity like $\mathbf{L D}_{50}>5000 \mathrm{mg} \mathrm{kg}{ }^{-1}$ i.p. or i.v. mouse (Figure 33). Particularly intensive

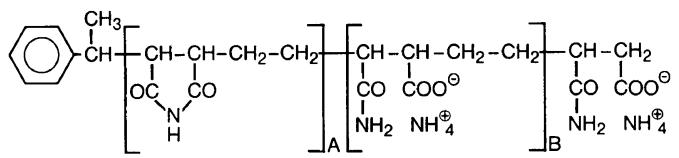

Carboxyimamidate

Carbethimer or NED 137

Monsanto Co.

$\bar{M}_{n} \approx 1700 ; A=14-25 w t \%, B=86-75 w t \%$

Figure 32. Structural formula of Carbethimer (Monsanto).

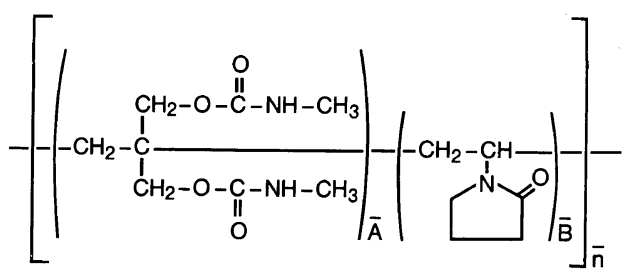

$$
\begin{aligned}
& \text { Copovithane=BAY i } 7433 \\
& \text { Bayer AG } \\
& \bar{M}_{n} \approx 5500 ; \bar{A}=1, \bar{B} \approx 4, \bar{n} \approx 8,4
\end{aligned}
$$

Figure 33. Structural formula of Copovithane (Bayer).

research has been carried out on BAY i $7433=$ Copovithane, a copolymer of $\approx 30 \%$ by weight 2 methylene-1,3-propanediyl-bis(methylcarbamate) and $\approx 70 \%$ by weight $N$-vinylpyrrolidone. This substance can be manufactured with very good reproducibility by free radical solution polymerization. The number average molecular weight $M_{n} \approx 5500$ was selected to ensure that the polymer is excreted totally through the kidneys. Acute and subchronic (three months) toxicity tests on rats, dogs and monkeys confirm the very low toxicity of Copovithane also established in the clinical phase-I studies.

In experiments with 8 different subcutaneous tumors in mice a single intravenous or intramuscular application of Copovithane, either prophylactic (e.g., 6 days before tumor transplantation, TT) or curative (e.g., 2 days after TT), resulted in 50 $80 \%$ inhibition of tumor growth (calculated on tumor weight) and $20-50 \%$ increase in survival times. The substance is very well tolerated, indicating a selective action on the tumor. Very recent tests 


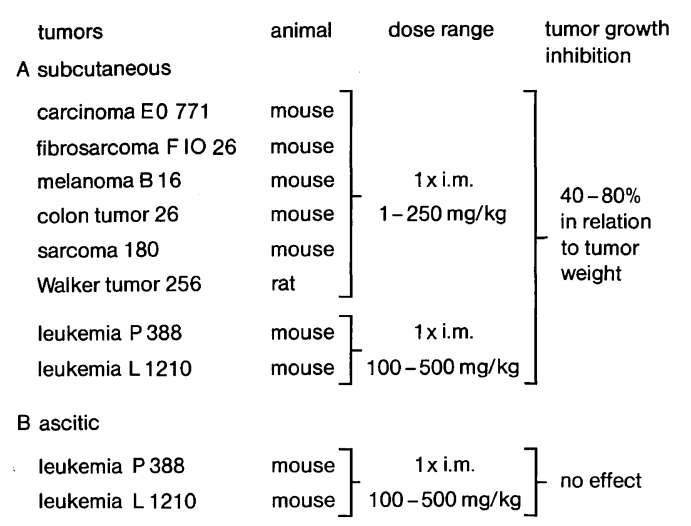

Figure 34. Results of experimental studies on tumor growth inhibition by Copovithane (Bayer).

have shown that the protein content of tumors in animals treated with Copovithane is significantly lower than in control tests. No apparent differences in DNA distribution were observed. Initial clinical tests have yielded encouraging results but these have still to be confirmed by further tests (Figure 34).

Remarkable as our success with Copovithane may be, we are still a long way from having a welltested, versatile or truly sensational cancer drug. We do not understand how the drug works, and this must be the starting point of future research. Rapid success in this area cannot be expected.

A more immediate possibility will be to apply develoments in polymer chemistry to biological objectives. Recent studies of microspheres and liposomes for instance open up new paths for research. These studies have been performed among others mainly by the groups of Rembaum in the USA and by Ringsdorf in Germany.

Conventional drugs are seriously hampered in their use and effectivity since they are rapidly distributed throughout the body and excreted. This is of particular importance if pharmacological highly active and often equally toxic materials are needed. The hope is that by carrying the drug attached to a macromolecular system specifically to the required site these problems can be overcome.

Microsphere systems (Figure 35) have been developed by several research groups for both diagnostic and therapeutic purposes. Of particular interest are immunomicrospheres which can be made from "naked" microspheres (as shown in the center of Figure 35) by attaching antibodies to its surface

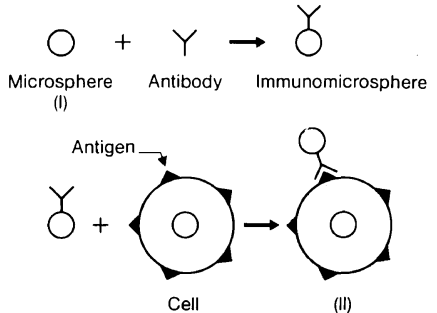

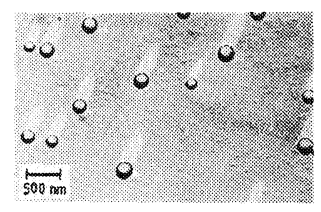

(I) "Naked" polymeric microspheres (D. Nerger, 1978)

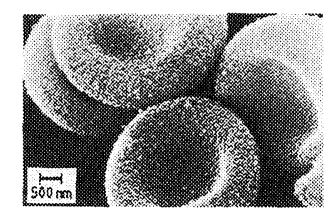

(II) Human red blood cells labeled first with rabbit anti-red blood cell antiserum and subsequently labeled with goat and subsequently labeled with goat to fluorescent polymeric microspheres to fluorescent polym
(A. Rembaum, 1979)

Figure 35. Preparation of immuno microspheres (I) and use thereof for specific cell labeling (II). Reprinted with permission from the author (D. Nerger, Ph.D. Thesis, Freiburg 1978) and from Marcel Dekker [A. Rembaum, S. P. S. Yen and R. S. Molday; J. Macromol. Sci. Chem., A13, 603 (1979)].

as a homing device. The group of Rembaum at California Institute of Technology has demonstrated that immunomicrospheres will form specific conjugates with antigene-sites. In this case the microspheres serve to lable human red blood cells.

Since recently through the discovery of Köhler and Milstein monoclonal antibodies became available it is now a challenge to prepare a suitable monoclonal-antibody-system that is for instance able to carry pharmacological active material to specific sites. First experiments in vitro of this kind have been made public the end of last year by the groups of Davis and Illum.

A probably even more complex challenge has been taken up by a number of researchers who try to mimic biological membranes, even cellular structures. The group of Ringsdorf, for instance, has been recently successful in preparing polymeric liposomes (Figure 36). Ringsdorf and coworkers have demonstrated that polymeric vesicles can be "uncorked" on command, for instance, by specificly triggered chemical reaction of non-copolymerized lipids in the vesicular shell of the synthetic liposome (see Figure 36).

Considering the accumulated wealth of knowl- 


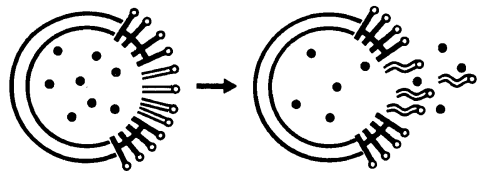

"Uncorking" of mixed polymeric liposomes

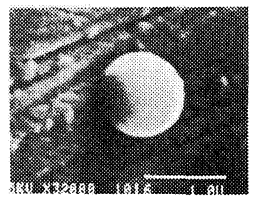

Scanning electron micrograph of a phase separated polymerized liposome before "pulling the cork"

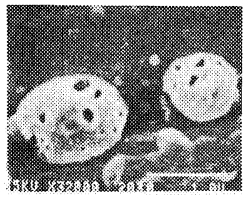

Scanning electron micrograph of an "uncorked liposome" after cleaving the disulfide linkage of the fluorocarbon lipid with dithionite

(H. Ringsdorf, 1984)

Figure 36. Synthetic polymeric liposomes and chemically triggered opening of the liposomes. Reprinted with permission from Hüthig and Wepf [R. Büschl, T. Folda, and H. Ringsdorf, Makromol. Chem. Suppl., 6, S. 252 (1984)].

edge in the traditional fields we have to ask how to bridge the gap between polymer and biological research. An answer to this question has been given by the research as mentioned above. Most answers are still completely unknown to us.

I think all of us agree that interesting results from both the scientific and the economic point of view must be looked for in areas where different disciplines overlap. We shall only gain a greater understanding of therapeutically active polymers if polymer chemists and biologists work together. Open- minded cooperation is the only way of bridging the wide gap that still exists between the different disciplines.

Is this area of research confined to the universities alone? We believe that the urgency and complexity of this research make it essential that work is carried out jointly by university and industrial laboratories. A fruitful cooperation of academia and industry will help to master the challenge of future polymer research.

The industrial aspects of polymer research are divided in two categories, the challenge of the inexpensive commodities, and that of the lowvolume, high-performance specialities. A company like Bayer with its roots in pharmaceutical chemistry cannot ignore functional polymer materials. Certainly, however, even the most successful of polymeric active ingredients will never keep our plastics plants working with total utilization of capacity. In this respect specialty polymers only do not satisfactorily meet the requirement mentioned at the beginning of this paper for products with a higher value added to help us to overcome capacity problems with commodity plastics bound to a cyclical economic development. Both, large volume polymers and sophisticated technologies need dedicated and creative research and unbiased cooperation with other fields. The only policy following the goal given by Akio Morita of Sony Corp. is, through persistent research, to let our own products become obsolete so that we can replace them. If we do not do it ourselves, our competitors will do it. But if we are successful then higher quality will also lead to higher quantities. 